\title{
Day-night variations in endothelial dysfunction markers and haemostatic factors in sleep apnoea
}

\author{
A. Barceló*, J. Piérola*, M. de la Peñađ, C. Esquinas ${ }^{+}$, M. Sanchez-de la Torre ${ }^{+, \S}$, \\ O. Ayllón*, A. Alonso", A.G.N. Agusti ${ }^{\S, f, * *}$ and F. Barbè $\grave{1}^{+, \S}$
}

ABSTRACT: Patients with sleep apnoea have a significant alteration in the day-night pattern of myocardial infarction and sudden cardiac death observed in the general population. The aim of this study was to investigate the influence of sleep apnoea on the diurnal variations in various haemostatic parameters (factor VII, von Willebrand factor and plasminogen activator inhibitor (PAI)-1) and markers of endothelial dysfunction (asymmetric dimethylarginine (ADMA) and soluble CD40 ligand (sCD40L)).

We studied 26 male patients with obstructive sleep apnoea syndrome (OSAS; 13 patients with severe OSAS (apnoea/hypopnoea index (AHI) $>30$ events $\cdot h^{-1}$ ) and 13 patients with mild-tomoderate OSAS (AHI $<30$ events $\left.\cdot h^{-1}\right)$ ) and 12 controls of similar body mass index (BMI) and waist circumference. In each subject, six different samples were obtained over $24 \mathbf{~ h}$.

Although all the markers values tended to be higher in patients with severe OSAS, differences did not reach statistical significance at any time. PAI-1 levels were significantly related to BMI $(p<0.001)$, mean $(p<0.001)$ and minimal $(p=0.047)$ nocturnal oxygenation saturation. ADMA levels were significantly related to arousal index $(p=0.046)$.

The results of this study suggest that day-night variations in factor VII:antigen (Ag), von Willebrand factor:Ag, PAI-1, sCD40L and ADMA levels may be dependent on either the obesity index or metabolic dysfunction rather than on sleep apnoea alone.

\section{KEYWORDS: Endothelial, sleep apnoea}

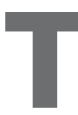

here is evidence that patients with obstructive sleep apnoea syndrome (OSAS) have an increased risk for cardiovascular diseases, including premature death from vascular events [1-5]. In the general population, cardiovascular $(\mathrm{CV})$ events predominantly occur in the first few hours after waking [6-8]. This has been explained on the basis of the circadian variations of heart rate, blood pressure, platelet aggregation and fibrinolytic activity [9-12]. In contrast, patients with OSAS show a marked variation of the day-night pattern of myocardial infarction and sudden cardiac death observed in the general population such that $\mathrm{CV}$ events occur preferentially in the middle of the night, while patients are sleeping $[13,14]$.

It appears that several factors involved in the development of cardiovascular disease are temporally regulated [15-19]. Vascular tone and endothelial function vary according to the time of day and there are differences between healthy individuals and patients with atherosclerotic disease with respect to the rhythm of nitric oxide (NO) production [20-22].

Circadian periodicity has been observed in components of the haemostatic system (plasminogen activator inhibitor (PAI)-1, factor VII and von Willebrand factor) $[19,23,24]$ and markers of endothelial damage (soluble CD40 ligand (sCD40L) and asymmetric dimethylarginine (ADMA)) [21, 25]. Whether an abnormal circadian pattern of endothelial function and thrombotic potential contributes to the altered distribution of CV events in OSAS is poorly understood. Circadian rhythms are likely to be affected by established CV risk factors, including obesity, ageing, diabetes and hypertension, that occur frequently in OSAS [21, 26-29]. A recent study shows that differences in the day-night rhythm of PAI-1 between OSAS patients and nonOSAS controls may not be independent of metabolic factors [30]. The present study was designed to investigate whether the circadian changes in haemostatic and endothelial markers observed in healthy subjects occur in patients with sleep
AFFILIATIONS

*Serveis de Anàlisis Cliniques,

"Unitat de Investigació,

-Pneumologia, Hospital Universitari Son Espases, CIBER Enfermedades Respiratorias (CIBERES),

${ }^{\S}$ Hospital Universitari Son Espases, CIBERES, Palma de Mallorca, +Hospital Universitari Santa MariaArnau de Vilanova, Lleida,

${ }^{f} F u n d a c i o ́$ Caubet-Cimera, Bunyola, and

**Institut del Tórax, Hospital Clínic, Barcelona, Spain.

CORRESPONDENCE

A. Barceló

Servei de Anàlisis Cliniques Hospital

Universitari Son Espases

Ctra. Valldemossa

79

07010 Palma de Mallorca

Spain

E-mail: antonia.barcelo@ssib.es

Received:

March 042011

Accepted after revision:

Aug 072011

First published online:

Aug 182011 
apnoea. To address this issue, we compared the diurnal variations in the concentration of various haemostatic parameters (factor VII, von Willebrand factor and PAI-1) and markers of endothelial dysfunction (ADMA and sCD40L) in patients with OSAS and in a control group of similar body mass index (BMI), waist circumference and metabolic profile.

\section{METHODS}

\section{Subjects and ethics}

We studied 26 male patients with OSAS (13 patients with severe OSAS (apnoea/hypopnoea index (AHI) $>30$ events $\cdot h^{-1}$ ) and 13 patients with mild-to-moderate OSAS (AHI $<30$ events $\left.\cdot \mathrm{h}^{-1}\right)$. As a reference group, we included 12 controls without OSAS. They had all been referred to the sleep laboratory for snoring or suspected OSAS. Each participant was interviewed and was informed in detail of the purpose of this study. They were matched for BMI $\left( \pm 3 \mathrm{~kg} \cdot \mathrm{m}^{-2}\right)$ and waist circumference $( \pm 5 \mathrm{~cm})$. The diagnosis of OSAS was established by full polysomnography (E-Series Compumedics, Abbotsford, Australia), including recording of oronasal flow, thoracoabdominal movements, ECG, submental and pre-tibial electromyography, electro-oculography, electroencephalography and transcutaneous measurement of arterial oxygen saturation. Apnoea was defined by the absence of airflow for $>10$ s. Hypopnoea was defined as any airflow reduction that lasted $>10 \mathrm{~s}$ and resulted in arousal or oxygen desaturation. We considered desaturation a decrease in arterial oxygen saturation $>4 \%$. The AHI was defined as the sum of the number of apnoeas plus hypopnoeas per hour of sleep.

No participant suffered from any chronic disease (diabetes, systemic hypertension, chronic obstructive pulmonary disease, liver cirrhosis, thyroid dysfunction, rheumatoid arthritis, chronic renal failure and/or psychiatric disorders), or was taking any type of medication. The study was approved by the Ethics Committee of our institution, and all the participants signed their consent after being fully informed of its goal and characteristics.

\section{Protocol}

Participants arrived at the sleep unit of our institution (Hospital Universitario Son Espases CIBERES, Palma de Mallorca, Spain) at 21:00 h, after fasting for at least $6 \mathrm{~h}$. A heparinised venous catheter (Introcan Safety®; Braun, Melsungen, Germany) was inserted into an antecubital vein to allow serial blood sampling throughout the night without disturbing sleep [31, 32]. From this catheter, six different samples $(20 \mathrm{~mL}$ each) were obtained during the next $24 \mathrm{~h}$ (22:00, 02:00, 06:00, 10:00, 14:00 and 18:00 h). Blood was collected into tubes containing EDTA $(10 \mathrm{~mL})$ and into tubes containing sodium citrate $(10 \mathrm{~mL})$. The sample obtained at $10.00 \mathrm{~h}$ was followed by an additional one $(10 \mathrm{~mL})$ collected into tubes without any anticoagulant for general biochemical assessment. Blood samples were immediately processed and centrifuged during $15 \mathrm{~min}$ at 2,500 $\times g$ (model CR4 22; Jouan S.A., Saint-Herblain, France). Serum and plasma were frozen at $-80^{\circ} \mathrm{C}$ until analysis.

During the study, participants remained in the hospital. Arterial blood pressure was measured between 08:00 and 10:00 h using a mercury sphygmomanometer after they had been seated for $>5 \mathrm{~min}$, with their arm resting on a standard support. During the day, they were allowed to rest or to just perform low-activity tasks and they ate a standardised threemeal diet.

\section{Haematological and biochemical analysis}

Blood cell counting was performed on fresh samples using automatic electronic cell counter (XE 2100, Sysmex Corp, Kobe, Japan). Measurements of glucose, cholesterol, triglycerides, uric acid, creatinine and liver enzymes (alanine transaminase (ALT), aspartate transaminase (AST) and $\gamma$-glutamyl transpeptidase (GGT)) were performed using a standard automated enzymatic methods on a Hitachi 917 biochemical analyser (Roche Diagnostics, Indianapolis, IN, USA). High-density lipoprotein cholesterol (HDLc) was measured by a homogeneous, enzymatic colorimetric method using a commercial reagent set (Roche Diagnostics). Low-density lipoprotein cholesterol (LDLc) was calculated using the Friedewald equation.

\section{ELISA assays}

Factor VII:antigen (Ag), von Willebrand:Ag, PAI-1, sCD40L and ADMA levels were determined by ELISA using commercially available kits (Diagnostica Stago, Asnieres, France (factor VII:Ag, von Willebrand:Ag and PAI-1); R\&D Systems Inc., Minneapolis, MN, USA (scD40L); and BioMedica Diagnostic systems, Vienna, Austria (ADMA)). Measurements were always performed in duplicate, and mean values were used for analysis. The intra-assay coefficients of variation were 3.5\% for factor VII:Ag, $6.1 \%$ for von Willebrand:Ag, 4.4\% for PAI-1, 5.1\% for sCD40L and $6.3 \%$ for ADMA.

\section{Statistical analysis}

Results are presented as percentages, median (interquartile range) or mean $\pm \mathrm{SD}$. Between-group comparisons were performed using the Kruskal-Wallis test. The Chi-squared test was used to compare categorical variables.

The distributions of endothelial and haemostatic variables were skewed and therefore the log transformation of these measures was applied before statistical analyses. ANOVA test for repeated measures was performed to compare with and within-group measurements of these variables at different times (22:00, 02:00, 06:00, 10:00, 14:00 and 18:00 h).

Comparison between groups for the concentration during follow-up of each marker was performed by the analysis of the areas under the curves (AUCs) using the Kruskal-Wallis test [33]. Separate intergroup comparisons for night (02:00 and 06:00 h), "morning" (10:00 and 14:00 h) or evening (18:00 and 22:00 h) AUCs were also calculated.

Correlations between the subjects' characteristics and haemostatic variables were explored using the Spearman rank test. Multiple regression analyses were used to confirm the significant associations detected with adjustment for age, BMI, waist circumference and smoking status.

Statistical significance was defined as $\mathrm{p}<0.05$. All statistical analyses were performed using SPSS version 17.0 (SPSS Inc., Chicago, IL, USA). 


\section{RESULTS}

Tables 1 and 2 show the main clinical characteristics and haematological and biochemical parameters of the two groups of patients and controls studied. By definition, patients with OSAS showed abnormal sleep parameters, whereas these variables were normal in controls. BMI, systolic and diastolic pressure, and glucose, triglycerides, cholesterol, creatinine, AST, ALT and GGT levels were similar between both groups of patients and controls, although the latter were slightly younger (table 1).

The number of circulating erythrocytes, leukocytes and platelets was similar in all the groups (table 2).

Figure 1 shows the circadian pattern of these variables observed in each group. Although all the markers values tended to be higher in patients with severe OSAS, these differences did not reach statistical significance at any time.

No differences between groups were detected between the AUC for PAI-1 $(p=0.30)$, for factor VII:Ag $(p=0.695)$, for von Willebrand factor:Ag $(p=0.534)$, for sCD40L $(p=0.990)$ and for ADMA $(p=0.395)$. Moreover, we did not find any differences between the AUC for these variables at three different intervals (morning, afternoon and night) during a 24-h period.

Spearman's correlation analysis showed that PAI-1 levels correlated positively with BMI $(\mathrm{r}=0.667, \mathrm{p}<0.001)$ and negatively with the mean $(\mathrm{r}=-0.596, \mathrm{p}<0.001)$ and minimal nocturnal oxygenation saturation $(r=-0.333, p=0.047)$ (fig. 2). The dependency of the association between PAI-1 and oxygenation saturation on measures of adiposity and smoking

TABLE 1 Characteristics of subjects studied

\begin{tabular}{|c|c|c|c|}
\hline & $\begin{array}{c}\text { Severe } \\
\text { OSAS }\end{array}$ & $\begin{array}{l}\text { Mild-to-moderate } \\
\text { OSAS }\end{array}$ & Controls \\
\hline Subjects $\mathrm{n}$ & 13 & 13 & 12 \\
\hline Age yrs & $43 \pm 2$ & $39 \pm 2$ & $37 \pm 2$ \\
\hline AHI events $\cdot h^{-1}$ & $59 \pm 6$ & $20 \pm 3$ & $6 \pm 1^{\star \star}$ \\
\hline Mean $\mathrm{Sa}, \mathrm{O}_{2} \%$ & $93 \pm 1$ & $95 \pm 1$ & $97 \pm 1^{\star *}$ \\
\hline Minimum $\mathrm{Sa}, \mathrm{O}_{2} \%$ & $80 \pm 2$ & $85 \pm 1$ & $90 \pm 1^{\star *}$ \\
\hline Arousal index & $51 \pm 7$ & $22 \pm 3$ & $8 \pm 2^{\star \star}$ \\
\hline Epworth scale & $9 \pm 1$ & $9 \pm 1$ & $8 \pm 1$ \\
\hline TC $90 \%$ & $22.3 \pm 7.2$ & $2.3 \pm 1.2^{*}$ & $1.0 \pm 0.5^{\star}$ \\
\hline TST min & $385.5 \pm 40.5$ & $335.5 \pm 70.5$ & $322.7 \pm 50.5$ \\
\hline REM sleep \% & $14.7 \pm 6.2$ & $14.3 \pm 8.3$ & $16.9 \pm 7.7$ \\
\hline BMI $\mathrm{kg} \cdot \mathrm{m}^{-2}$ & $28 \pm 1$ & $27 \pm 1$ & $27 \pm 1$ \\
\hline Waist circumference $\mathrm{cm}$ & $100 \pm 2$ & $98 \pm 3$ & $96 \pm 3$ \\
\hline Neck circumference $\mathbf{c m}$ & $41 \pm 1$ & $40 \pm 1$ & $39 \pm 1$ \\
\hline SBP $\mathrm{mmHg}$ & $131 \pm 3$ & $123 \pm 3$ & $124 \pm 4$ \\
\hline DBP $\mathrm{mmHg}$ & $84 \pm 2$ & $72 \pm 3$ & $74 \pm 2$ \\
\hline Smokers & $3(23)$ & $4(31)$ & $5(41)$ \\
\hline
\end{tabular}

Data are presented as mean $\pm \mathrm{SD}$ or $\mathrm{n}(\%)$, unless otherwise stated. OSAS: obstructive sleep apnoea syndrome; $\mathrm{AHI}$ : apnoea/hypopnoea index; $\mathrm{Sa}, \mathrm{O}_{2}$ : arterial oxygen stauration; TC 90: \% time with $\mathrm{Sa}_{1} \mathrm{O}_{2}<90 \%$; TST: total sleep time; REM: rapid eye movement; BMI: body mass index; SBP: systolic blood pressure, DBP: diastolic blood pressure. *: $p<0.05$ versus severe OSAS **: $\mathrm{p}<0.01$ versus OSAS

\begin{tabular}{|c|c|c|c|}
\hline & $\begin{array}{l}\text { Severe } \\
\text { OSAS }\end{array}$ & $\begin{array}{c}\text { Mild-to-moderate } \\
\text { OSAS }\end{array}$ & Controls \\
\hline Subjects $n$ & 13 & 13 & 12 \\
\hline Glucose $\mathrm{mg} \cdot \mathrm{dL}^{-1}$ & $97 \pm 2$ & $97 \pm 3$ & $98 \pm 3$ \\
\hline $\begin{array}{l}\text { Triglycerides } \\
\mathrm{mg} \cdot \mathrm{dL}^{-1}\end{array}$ & $155 \pm 22$ & $136 \pm 21$ & $158 \pm 37$ \\
\hline Cholesterol $\mathrm{mg} \cdot \mathrm{dL}^{-1}$ & $200 \pm 6$ & $183 \pm 11$ & $170 \pm 7^{\star}$ \\
\hline $\mathrm{HDLc} \mathbf{m g} \cdot \mathrm{dL}^{-1}$ & $45 \pm 3$ & $46 \pm 4$ & $40 \pm 4$ \\
\hline $\mathrm{LDLc} \mathbf{m g} \cdot \mathrm{dL}^{-1}$ & $128 \pm 6$ & $111 \pm 11$ & $98 \pm 3^{*}$ \\
\hline Uric acid $\mathrm{mg} \cdot \mathrm{dL}^{-1}$ & $6.1 \pm 0.4$ & $6.0 \pm 0.4$ & $6.0 \pm 0.3$ \\
\hline Creatinine $\mathrm{mg} \cdot \mathrm{dL}^{-1}$ & $0.94 \pm 0.04$ & $0.93 \pm 0.02$ & $0.91 \pm 0.02$ \\
\hline AST $U \cdot L^{-1}$ & $23 \pm 2$ & $23 \pm 3$ & $24 \pm 2$ \\
\hline$A L T U \cdot L^{-1}$ & $28 \pm 3$ & $27 \pm 2$ & $27 \pm 2$ \\
\hline GGT $U \cdot L^{-1}$ & $32 \pm 3$ & $30 \pm 2$ & $30 \pm 2$ \\
\hline $\begin{array}{l}\text { Erythrocytes } \\
\qquad \times 10^{6} \text { cells } \mu \mathrm{L}^{-1}\end{array}$ & $5.1 \pm 0.1$ & $5.0 \pm 0.1$ & $5.0 \pm 0.1$ \\
\hline $\begin{array}{l}\text { Leukocytes } \\
\qquad \times 10^{3} \text { cells } \mu \mathrm{L}^{-1}\end{array}$ & $8.0 \pm 0.6$ & $7.3 \pm 0.3$ & $7.8 \pm 0.4$ \\
\hline $\begin{array}{l}\text { Platelets } \\
\qquad \times 10^{3} \text { cells } \mu \mathrm{L}^{-1}\end{array}$ & $222 \pm 12$ & $228 \pm 13$ & $237 \pm 19$ \\
\hline
\end{tabular}

Data are presented as mean $\pm \mathrm{SD}$, unless otherwise stated. OSAS: obstructive sleep apnoea syndrome; HDLc: high-density lipoprotein cholesterol; LDLc: lowdensity lipoprotein cholesterol; AST: aspartate transaminase; ALT: alanine transaminase; GGT: $\gamma$-glutamyl transpeptidase. * : $\mathrm{p}<0.05$ versus severe OSAS

status was explored in a multiple regression analysis. Significant associations were diminished, but not eliminated, after adjustment for age, BMI, waist circumference and smoking status (mean oxygenation saturation, $\mathrm{p}=0.031$ ).

ADMA levels were also significantly related to the arousal index ( $p=0.046)$ (fig. 2).

\section{DISCUSSION}

This study shows that day-night variations in factor VII:Ag, von Willebrand factor:Ag, PAI-1, sCD40L and ADMA levels are not significantly different between patients with OSAS and controls without OSAS of similar adiposity and metabolic profile. Our results suggest that sleep apnoea does not have any direct effect on the oscillations of these haemostatic substances. Nevertheless, it is possible that the procoagulant consequences of sleep apnoea may become apparent in the presence of comorbidities, such as the metabolic syndrome.

Coagulation and fibrinolysis may influence cardiovascular risk in OSAS, but the relationship of adiposity with these processes is unclear [34]. Factor VII, von Willebrand factor, representatives of the haemostatic system and PAI-1, as the most important inhibitor of the fibrinolytic system, have been associated with visceral obesity [35-37]. In addition, adipose tissue has emerged as a key secretory organ that may regulate CD40L expression, suggesting a novel mechanism that accounts for the prothrombotic state of obese individuals and patients with metabolic syndrome [38, 39].

In the general population, acute $\mathrm{CV}$ events occur frequently in the early morning hours, when there is a marked rise in neural 

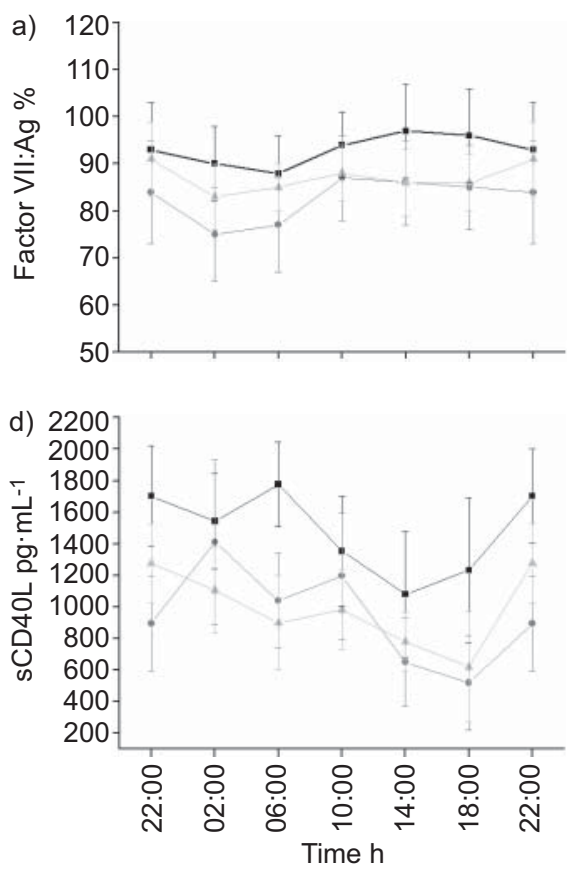
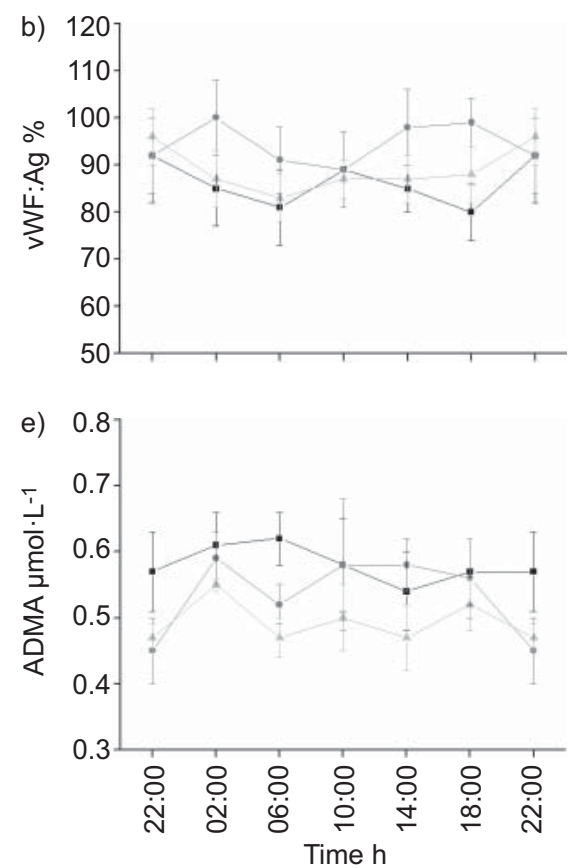

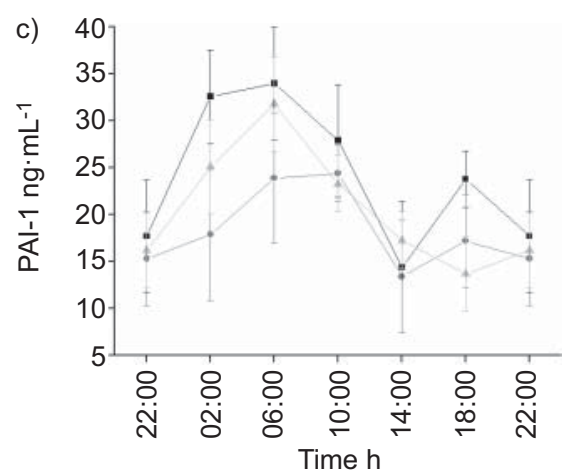

- - Severe OSAS

- Mild-to-moderate OSAS

- Controls

FIGURE 1. Mean values of a) factor VII: antigen (Ag), b) von Willebrand factor (VWF):Ag, C) plasminogen activator inhibitor (PAI)-1, d) soluble CD40 ligand (sCD40L) and e) asymmetric dimethylarginine (ADMA) at different times during the day in both groups of patients and controls. OSAS: obstructive sleep apnoea syndrome.

and hormonal sympathetic activity, increased platelet activity and hypercoagulability [6, 8, 10, 40]. By contrast, in patients with OSAS, the timing of myocardial infarction and sudden death shifts from the morning hours to the night, while the patient is actually sleeping $[13,14]$. The mechanisms by which this occurs are unclear. There is an intimate relationship between the circadian clock, metabolism and obesity [41, 42], and several studies have shown that diabetic patients exhibit a blunted circadian variation in haemostatic and fibrinolytic factors potentially associated with morning peaks of cardiovascular events [26, 29]. The current study assesses the circadian behaviour of these biomarkers in two groups of patients with OSAS and in a control group with a similar degree of obesity. There were no significant differences in the median values of these markers at different intervals between the three groups. Despite the fact that all markers values tended to be higher in patients with severe OSAS, these differences not reached statistical significance at any time. Nevertheless, the fact that our results suggest that the changes in these patterns may be dependent on the obesity index or metabolic dysfunction rather than on sleep apnoea alone does not mean that they are irrelevant in the pathogenesis of cardiovascular complications in these patients. Metabolic and hormonal aspects should be considered in future studies to test this hypothesis.

Several studies that have assessed haemostasis parameters in healthy subjects and patients with a history of coronary artery disease have shown that, despite the higher activity of PAI-1 in patients, the periodicity of changes was maintained in both groups. In our study, the circadian pattern of PAI-1 found in the controls was still present in the patients, albeit at a higher level. PAI-1 was associated with BMI and mean and minimum nocturnal oxygenation saturation. In a recent study, vON KÄNEL
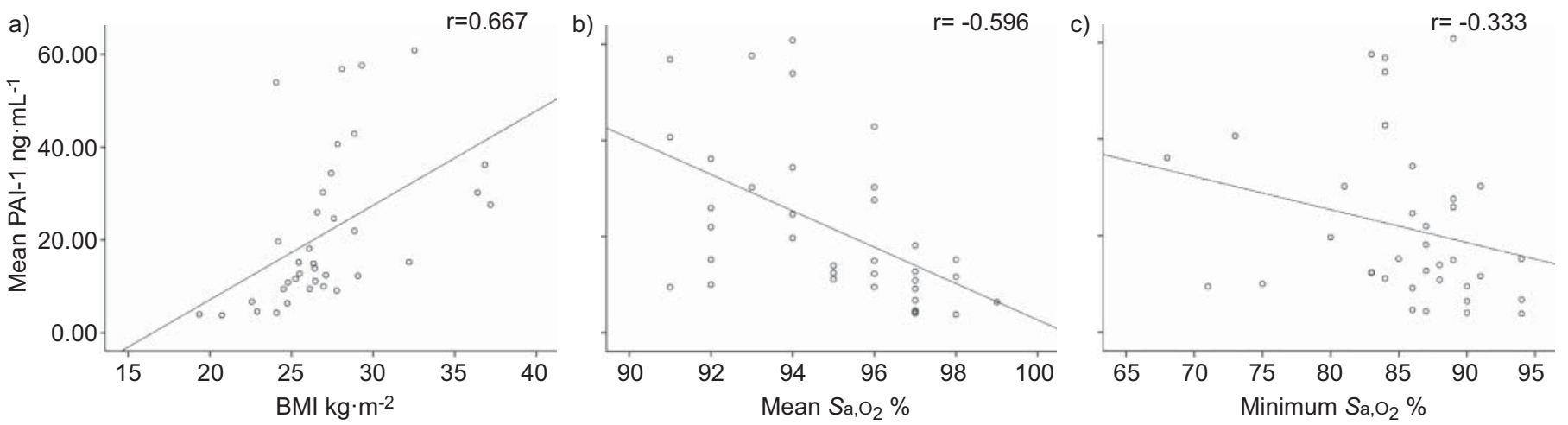

FIGURE 2. Relationship between plasminogen activator inhibitor (PAl)-1 and a) body mass index (BMI), and b) minimum and c) mean nocturnal arterial oxygen saturation $\left(\mathrm{Sa}, \mathrm{O}_{2}\right)$. 
et al. [30] found that the relationship between OSAS and PAI-1 was attenuated after controlling for BMI and mean arterial pressure. We did not include hypertensive subjects and, even though most of this association was explained by central obesity, PAI-1 levels were independently associated with indices of nocturnal hypoxia, even after adjusting for confounders. Furthermore, recent results of the Cleveland Family Study provide evidence for a positive relationship between OSA and PAI-1 levels [43]. These observations suggest a potential role of PAI-1 in the link between obesity, OSAS and CV risk.

Vascular tone and the concentration of NO metabolites in plasma exhibit a circadian variation [21]. Plasma concentrations of ADMA are elevated in several clinical syndromes associated with increased cardiovascular risk [44]. We have previously shown that plasma ADMA levels are elevated in patients with OSAS [45]. However, there is also evidence that ADMA levels are higher in obese and insulin-resistant individuals [46]. In the current study, the ADMA mean values tended to be higher in patients with severe OSAS but these differences did not reached any statistical significance. These results suggest that the concentration of ADMA may vary in OSAS according to the degree of obesity and metabolic disturbances. There was a significant correlation, however, between ADMA levels and the arousal index, suggesting a possible additional mechanism by which OSA may influence ADMA levels and lead to endothelial dysfunction.

One potential limitation of our study is that it included only male subjects. Furthermore, none of the participants described symptoms associated with excessive daytime sleepiness. As a consequence, our data cannot automatically be extrapolated to female patients or patients with excessive daytime sleepiness.

Compared with controls, patients with OSAS showed a higher variability in mean levels of PAI-1 at different times. This implies that other factors, not studied here, may be involved in these changes. Obesity may influence the circadian rhythms of cardiovascular and metabolic markers. The fact that other factors were not related to BMI, in either the patients or the controls, might be explained by the narrow range of BMI in the subjects studied herein. Nevertheless, hormonal aspects should be considered in the future.

Furthermore, although the control group had a very similar metabolic profile to that of the OSAS groups, the sample size limits the conclusions, and large studies should be carried out to evaluate the role of these haemostatic factors in the process of cardiovascular complications in patients with sleep apnoea.

In conclusion, the results of this study indicate that the daynight variations in the levels of several endothelial markers and haemostatic factors are not different between patients with sleep apnoea and controls of a similar weight. It is becoming increasingly clear that the circadian clock and metabolism directly influence one another. The search for additional factors that may contribute to better understanding the links between OSAS, metabolism and cardiovascular disease is highly desirable.

\section{SUPPORT STATEMENT}

Supported, in part, by SEPAR and Fondo de Investigaciones Sanitarias 07/906.

\section{STATEMENT OF INTEREST}

None declared.

\section{ACKNOWLEDGEMENTS}

We thank M. Bosch (Servei de Pneumologia, Hospital Son Espases, Palma de Mallorca, Spain) and M. Iglesias (Servei de Desarrollo, Hospital Universitario Son Espases, Palma de Mallorca) for their assistance in the coordination of the study.

\section{REFERENCES}

1 Pack AI, Gislason T. Obstructive sleep apnea and cardiovascular disease: a perspective and future directions. Prog Cardiovasc Dis 2009; 51: 434-451.

2 Marin JM, Carrizo SJ, Vicente E, et al. Long term cardiovascular outcomes in men with obstructive sleep apnea. Effects of treatment with CPAP. Lancet 2005; 365: 1046-1053.

3 Bradley TD, Floras JS. Obstructive sleep apnoea and its cardiovascular consequences. Lancet 2009; 373: 82-93.

4 Somers VK, White DP, Amin R, et al. Sleep apnea and cardiovascular disease: an American Heart Association/American College of Cardiology Foundation Scientific Statement from the American Heart Association Council for High Blood Pressure Research Professional Education Committee, Council on Clinical Cardiology, Stroke Council, and Council On Cardiovascular Nursing. In collaboration with the National Heart, Lung, and Blood Institute National Center on Sleep Disorders Research (National Institutes of Health). Circulation 2008; 118: 1080-1111.

5 Hernandez C, Duran-Cantolla J, Lloberes P, et al. Novedades en la epidemiología, la historia natural,el diagnóstics y el tratamiento del síndrome de apneas-hipopneas durante el sueño [Innovations in the epidemiology, natural history, diagnosis and treatment of sleep apnea-hypopnea syndrome]. Arch Bronconeumol 2009; 45: Suppl. 1, 3-10.

6 Muller JE. Circadian variation and triggering of acute coronary events. Am Heart J 1999; 137: S1-S8.

7 Goldberg RJ, Brady P, Muller JE, et al. Time of onset of symptoms of acute myocardial infarction. Am J Cardiol 1990; 66: 140-144.

8 Cohen MC, Rohtla KM, Lavery CE, et al. Meta-analysis of the morning excess of acute myocardial infarction and sudden cardiac death. Am J Cardiol 1997; 79: 1512-1516.

9 Huikuri HV, Niemela MJ, Ojala S, et al. Circadian rhythms of frequency domain measures of heart rate variability in healthy subjects and patients with coronary artery disease. Effects of arousal and upright posture. Circulation 1994; 90: 121-126.

10 Tofler GH, Brezinski D, Schafer AI, et al. Concurrent morning increase in platelet aggregability and the risk of myocardial infarction and sudden cardiac death. N Engl J Med 1987; 316: 1514-1518.

11 Andreotti F, Kluft C. Circadian variation of fibrinolytic activity in blood. Chronobiol Int 1991; 8: 336-351.

12 Jovicic A, Mandic S. Circadian variations of platelet aggregability and fibrinolytic activity in healthy subjects. Thromb Res 1991; 62 $65-74$

13 Gami AS, Howard DE, Olson EJ, et al. Day-night pattern of sudden death in obstructive sleep apnea. N Engl J Med 2005; 352: 1206-1214.

14 Kuniyoshi FH, Garcia-Touchard A, Gami AS, et al. Day-night variation of acute myocardial infarction in obstructive sleep apnea. J Am Coll Cardiol 2008; 52: 343-346.

15 Walters J, Skene D, Hampton SM, et al. Biological rhythms, endothelial health and cardiovascular disease. Med Sci Monit 2003 9: RA1-RA8.

16 Keaney JF Jr, Weaver DR. Vascular rhythms and adaptation: do your arteries know what time it is? Circulation 2009; 119: 1463-1466. 
17 Decousus H, Boissier C, Perpoint B, et al. Circadian dynamics of coagulation and chronopathology of cardiovascular and cerebrovascular events. Future therapeutic implications for the treatment of these disorders? Ann NY Acad Sci 1991; 618: 159-165.

18 Kapiotis S, Jilma B, Quehenberger P, et al. Morning hypercoagulability and hypofibrinolysis. Diurnal variations in circulating activated factor VII, prothrombin fragment F1+2, and plasminplasmin inhibitor complex. Circulation 1997; 96: 19-21.

19 Pinotti M, Bertolucci C, Portaluppi F, et al. Daily and circadian rhythms of tissue factor pathway inhibitor and factor VII activity. Arterioscler Thromb Vasc Biol 2005; 25: 646-649.

20 Otto ME, Svatikova A, Barretto RB, et al. Early morning attenuation of endothelial function in healthy humans. Circulation 2004; 109: 2507-2510.

21 Bode-Boger SM, Boger RH, Kielstein JT, et al. Role of endogenous nitric oxide in circadian blood pressure regulation in healthy humans and in patients with hypertension or atherosclerosis. J Investig Med 2000; 48: 125-132.

22 Boger RH, Bode-Boger SM, Szuba A, et al. Asymmetric dimethylarginine (ADMA): a novel risk factor for endothelial dysfunction: its role in hypercholesterolemia. Circulation 1998; 98: 1842-1847.

23 Bridges $A B$, McLaren $M$, Scott NA, et al. Circadian variation of tissue plasminogen activator and its inhibitor, von Willebrand factor antigen, and prostacyclin stimulating factor in men with ischaemic heart disease. Br Heart J 1993; 69: 121-124.

24 Chrusciel P, Goch A, Banach M, et al. Circadian changes in the hemostatic system in healthy men and patients with cardiovascular diseases. Med Sci Monit 2009; 15: RA203-RA208.

25 Dominguez-Rodriguez A, Abreu-Gonzalez P, Garcia-Gonzalez MJ, et al. Diurnal variation of soluble CD40 ligand in patients with acute coronary syndrome. Soluble CD40 ligand and diurnal variation. Thromb Res 2009; 123: 617-621.

26 Aronson D, Weinrauch LA, D'Elia JA, et al. Circadian patterns of heart rate variability, fibrinolytic activity, and hemostatic factors in type I diabetes mellitus with cardiac autonomic neuropathy. Am J Cardiol 1999; 84: 449-453.

27 Shaw E, Tofler GH. Circadian rhythm and cardiovascular disease. Curr Atheroscler Rep 2009; 11: 289-295.

28 Rudic RD, Fulton DJ. Pressed for time: the circadian clock and hypertension. J Appl Physiol 2009; 107: 1328-1338.

29 Rana JS, Mukamal KJ, Morgan JP, et al. Circadian variation in the onset of myocardial infarction: effect of duration of diabetes. Diabetes 2003; 52: 1464-1468.

30 von Känel R, Natarajan L, Ancoli-Israel S, et al. Day/night rhythm of hemostatic factors in obstructive sleep apnea. Sleep 2010; 33: 371-377.
31 McLaren G, Hanna C, Mills L, et al. Comparison of sampling methods for obtaining accurate coagulation values in hemodialysis patients with heparinized central venous catheters. Nephrol Nurs J 2001; 28: 632-636.

32 Powers JM. Obtaining blood samples for coagulation studies from a normal saline lock. Am J Crit Care 1999; 8: 250-253.

33 Matthews JN, Altman DG, Campbell MJ, et al. Analysis of serial measurements in medical research. BMJ 1990; 300: 230-235.

34 von Känd R, Dimsdale JE. Hemostatic alterations in patients with obstructive sleep apnea and the implications for cardiovascular disease. Chest 2003; 124: 1956-1967.

35 Godsland IF, Crook D, Proudler AJ, et al. Hemostatic risk factors and insulin sensitivity, regional body fat distribution, and the metabolic syndrome. J Clin Endocrinol Metab 2005; 90: 190-197.

36 Vambergue A, Rugeri L, Gaveriaux V, et al. Factor VII, tissue factor pathway inhibitor, and monocyte tissue factor in diabetes mellitus: influence of type of diabetes, obesity index, and age. Thromb Res 2001; 101: 367-375.

37 Reaven GM, Scott EM, Grant PJ, et al. Hemostatic abnormalities associated with obesity and the metabolic syndrome. J Thromb Haemost 2005; 3: 1074-1085.

38 Unek IT, Bayraktar F, Solmaz D, et al. The levels of soluble CD40 ligand and C-reactive protein in normal weight, overweight and obese people. Clin Med Res 2010; 8: 89-95.

39 Unek IT, Bayraktar F, Solmaz D, et al. Enhanced levels of soluble CD40 ligand and C-reactive protein in a total of 312 patients with metabolic syndrome. Metabolism 2010; 59: 305-313.

40 Muller JE, Tofler GH, Willich SN, et al. Circadian variation of cardiovascular disease and sympathetic activity. J Cardiovasc Pharmacol 1987; 10: Suppl. 2, S104-S109.

41 Froy O. Metabolism and circadian rhythms - implications for obesity. Endocr Rev 2010; 31: 1-24.

42 Laposky AD, Bass J, Kohsaka A, et al. Sleep and circadian rhythms: key components in the regulation of energy metabolism. FEBS Lett 2008; 582: 142-151.

43 Mehra R, Xu F, Babineau DC, et al. Sleep-disordered breathing and prothrombotic biomarkers: cross-sectional results of the Cleveland Family Study. Am J Respir Crit Care Med 2010; 182: 826-833.

44 Boger RH, Vallance P, Cooke JP. Asymmetric dimethylarginine (ADMA): a key regulator of nitric oxide synthase. Atheroscler Suppl 2003; 4: 1-3.

45 Barcelo A, de la Peña M, Ayllon O, et al. Increased plasma levels of asymmetric dimethylarginine and soluble CD40 ligand in patients with sleep apnea. Respiration 2009; 77: 85-90.

46 Abbasi F, Asagmi T, Cooke JP, et al. Plasma concentrations of asymmetric dimethylarginine are increased in patients with type 2 diabetes mellitus. Am J Cardiol 2001; 88: 1201-1203. 